\title{
A case of Rathke's Cleft Cyst Associated with Diabetes Insipidus and Hashimoto's Thyroiditis
}

\author{
Hiroyuki KoshiYama, Yuzuru Kato**, Hiroshi MaSUTANI, Noboru HaShimoto* \\ and Hiroo IMURA
}

\begin{abstract}
A 71-year-old woman with symptomatic Rathke's cleft cyst is reported. She had visual disturbance, diabetes insipidus and hypopituitarism. Imaging studies with computed tomography and magnetic resonance image revealed the presence of suprasellar mass. After the transsphenoidal surgery and treatment with DDAVP, her symptoms showed an improvement.
\end{abstract}

Key words: Rathke's cleft cyst, Diabetes insipidus, Hypopituitarism, Magnetic resonance image

It is suggested that an intrapituitary cyst may be derived from remnants of Rathke's pouch, an invagination of the stomodeum. They are called Rathke's cleft cysts $(1,2)$. Although most of these cysts are clinically silent (3), there have been more than 60 symptomatic cases reported in the literature (1, 4-13).

We report a case of Rathke's cleft cyst with diabetes insipidus, in which endocrinological examinations and imaging studies with computed tomography (CT) as well as magnetic resonance image (MRI) were performed.

\section{CASE REPORT}

A 71-year-old woman was referred to our clinic with a history of moderate thirst for 2 years, and that of polyuria, polydipsia and visual disturbance for 3 months. She had no headache and nausea.

Examination. Physical examination revealed dry skin and diffuse goiter. She had superior bitemporal defect of the visual field. Blood chemistry showed no abnormal findings except for high total cholesterol $(249 \mathrm{mg} / \mathrm{dl})$ and serum $\mathrm{Na}$ level (153
$\mathrm{mEq} / \mathrm{l})$, both of which were consistently obtained. Plain X-ray of the skull showed slightly enlarged sella turcica with double floor image (Fig. 1). Brain CT indicated an intrasellar isodense mass lesion with suprasellar extension that was not enhanced with contrast material (Fig. 2), resulting in the diagnosis of possible pituitary adenoma. MRI more remarkedly revealed a well-defined mass above the normal anterior pituitary gland, which distended to the floor of the third ventricule. It showed slightly low intensity on T1-weighed image (Fig. 3) and high intensity on $\mathrm{T} 2$-weighed image. The chiasm was shifted upward. Its tentative diagnosis was craniopharyngioma.

Endocrinological examination. As shown in Fig. 4, both plasma adrenocorticotropic hormone $(\mathrm{ACTH})$ and cortisol responded normally to both insulin-induced hypoglycemia $(0.1 \mathrm{U} / \mathrm{kg}$, iv) and corticotropin-releasing factor (CRF) stimulation test $(100 \mu \mathrm{g}$, iv). Plasma luteinizing hormone (LH) and follicle-stimulating hormone (FSH) levels were low $(3.3 \mathrm{mIU} / \mathrm{ml}$ and $<1.95 \mathrm{mIU} / \mathrm{ml})$ and did not respond to luteinizing hormone-releasing hormone

From The Second Division, Department of Internal Medicine and *Department of Neurosurgery, Kyoto University Faculty of Medicine, Kyoto and **the First Division, Department of Medicine, Shimane Medical University, Izumo

Received for publication November 29, 1988

Reprint request to: Hiroyuki Koshiyama, The Second Division, Department of Internal Medicine, 54 Shogoin Kawahara-cho, Sakyo-ku, Kyoto 606, Japan. 


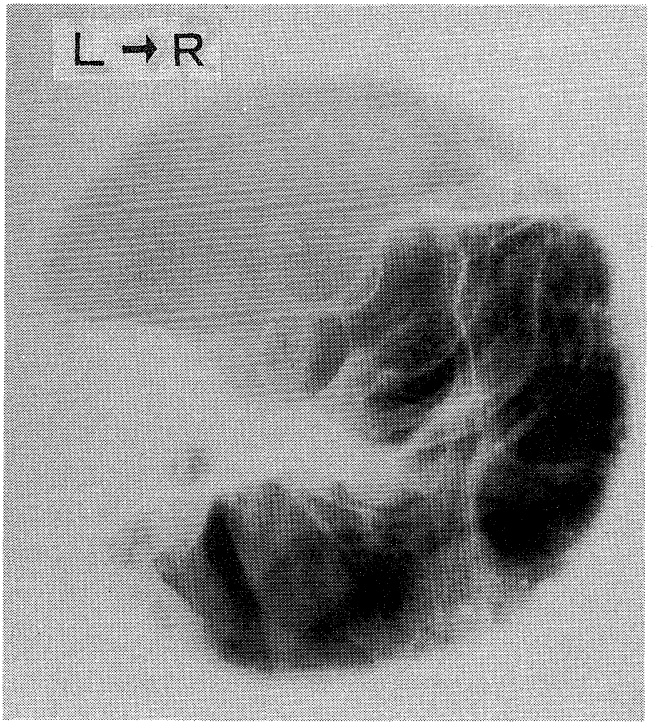

Fig. 1. Plain lateral view of X-ray examination of the skull. The sella was slightly enlarged with double floor.

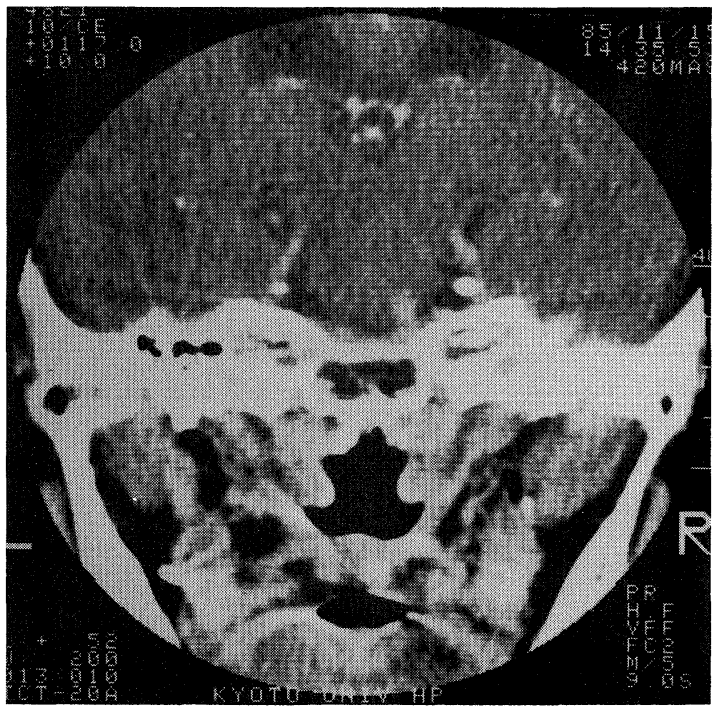

Fig. 2. Preoperative CT with contrast enhancement showed a nonenhancing isodense mass extending from the pituitary fossa to the suprasellar region.

(LHRH) $(100 \mu \mathrm{g}$, iv). Plasma thyroid-stimulating hormone (TSH) poorly responded to thyrotropinreleasing hormone (TRH, $500 \mu \mathrm{g}$, iv), whereas plasma plasma prolactin (PRL) responded normally to TRH. Plasma growth hormone $(\mathrm{GH})$ responded subnormally to insulin injection $(0.1 \mathrm{U} / \mathrm{kg}$, iv) and

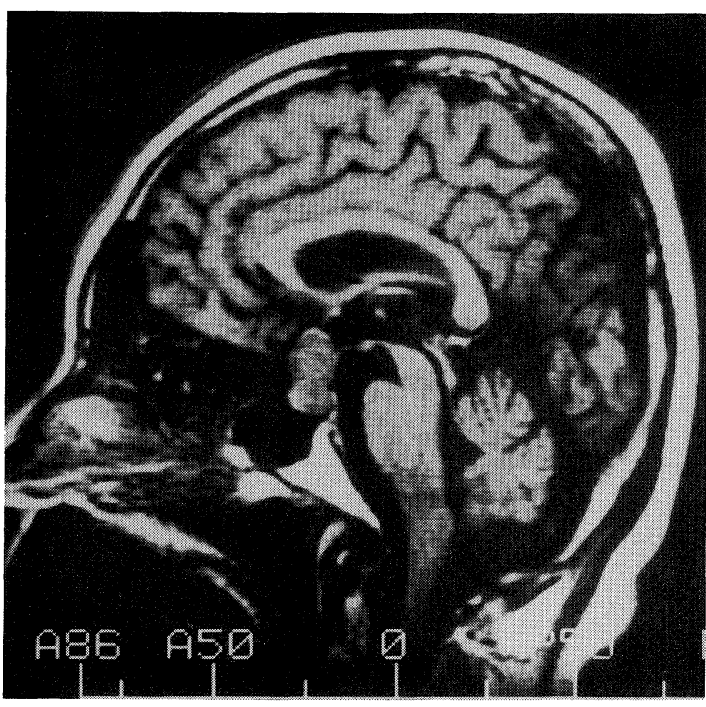

Fig. 3. MRI (T1-weighed image) showed a well-defined mass which was extended from the sellar floor to the third ventricle.

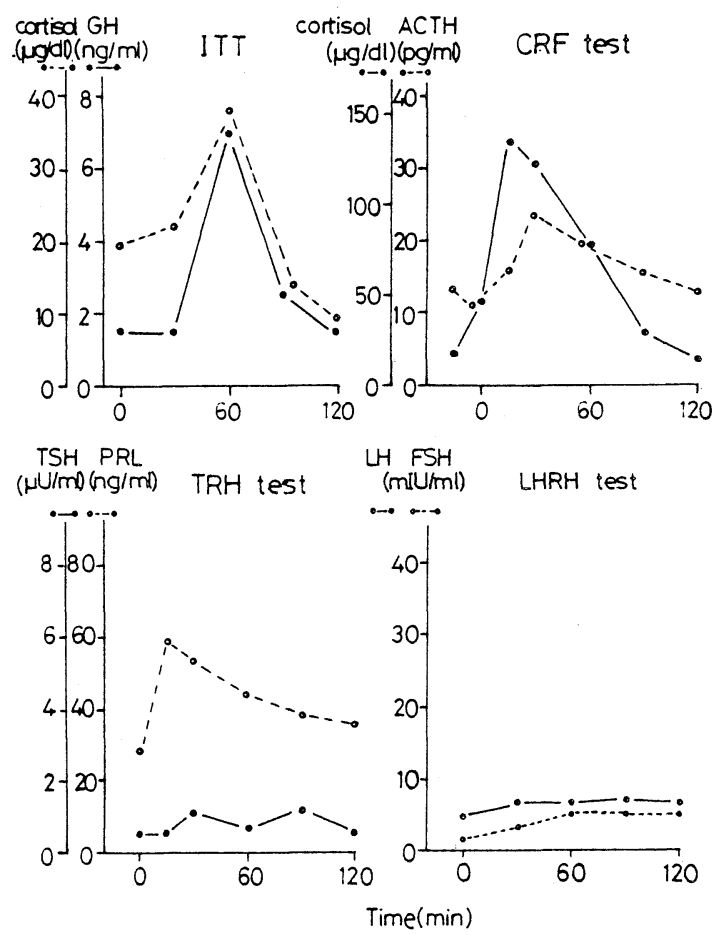

Fig. 4. Preoperative endocrinological examinations of the anterior pituitary. Insulin $(0.1 \mathrm{U} / \mathrm{kg}), \mathrm{CRF}(100 \mu \mathrm{g}), \mathrm{TRH}$ $(500 \mu \mathrm{g})$ and LHRH $(100 \mu \mathrm{g})$ were administered intravenously as a bolus injection. Plasma GH, ACTH, cortisol, TSH, PRL, LH and FSH levels were measured by specific radioimmunoassays. 
arginine infusion $(30 \mathrm{~g}$, iv), with a peak value of 7.0 $\mathrm{ng} / \mathrm{ml}$ and $6.0 \mathrm{ng} / \mathrm{ml}$, respectively.

In Miller-Moses test, urinary osmolarity did not rise after water deprivation and responded to vasopressin (100 mU, iv) (Fig. 5). Serum T3 and T4 levels were $79 \mathrm{ng} / \mathrm{dl}$ and $5.7 \mu \mathrm{g} / \mathrm{dl}$, respectively. Thyroid microsomal antibodies were positive $\left(10 \times 2^{11}\right)$. Ultrasonography of thyroid gland revealed diffuse heterogenous goiter. Thyroid scintigraphy showed low trapping. Histological examination by needle biopsy of the goiter revealed Hashimoto's chronic thyroiditis.

Based on these data, she was clinically diagnosed as diabetes insipidus due to suprasellar extension of intrasellar tumor and chronic thyroiditis. She was referred to the department of neurosurgery for transsphenoiodal surgery.

Operation. Transsphenoidal surgery revealed that a cyst was present above the normal anterior pituitary gland. The cyst wall was smooth and the pituitary stalk was displaced backward by the mass. Whitish, mucoid content of the cyst was aspirated. The histologic diagnosis was Rathke's cleft cyst.

Postoperative course. GH responded poorly to insulin and arginine, whereas cortisol normally responded to insulin. TSH and PRL responded normally to TRH. LH and FSH well responded to

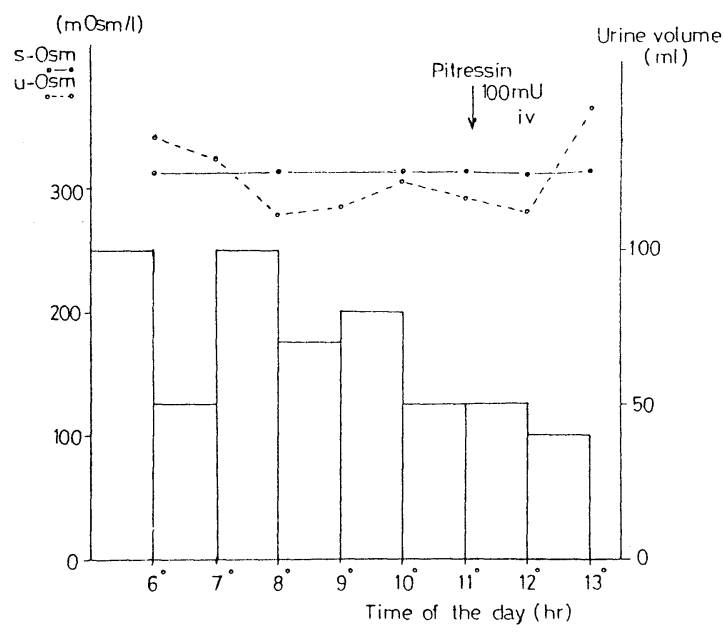

Fig. 5. Water deprivation test and vasopressin test (Miller-Moses test). When body weight loss exceeded 3\% of the body weight after overnight water deprivation, vasopressin (Pitressin, $100 \mathrm{mU}$ ) was administered intravenously as a bolus injection.
LHRH, although their basal levels remained low. Miller-Moses test indicated the presence of partial diabetes insipidus.

Serum thyroid hormone levels were within normal limits. Thirst and polyuria disappeared by intranasal administration of L-desamino-8-D-arginine vasopressin (DDAVP) twice a day (5 $\mu \mathrm{g} 2 /$ day). Visual disturbance was slightly improved.

\section{DISCUSSION}

Although symptomatic Rathke's cleft cysts are rare (13), Kobayashi et al. described 37 symptomatic cases in review of literature (6). The most frequent symptoms were visual disturbance ( 25 cases) and hypopituitarism (20 cases). Diabetes insipidus was found in only 6 cases. Our case showed visual disturbance and diabetes insipidus, which appeared at the age of 70. There has been no report on the case of Rathke's cleft cyst with chronic thyroiditis.

Steinberg et al. suggested that symptomatic Rathke's cleft cysts might be more common than generally considered, since patients with Rathke's cleft cysts have been found more frequently by using new imaging techniques and that some might have been misdiagnosed as craniopharyngioma (3). Although Rathke's cleft cysts are found incidentally at autopsy, most of them are too small to produce any symptom. When they are enlarged sufficiently enough to compress the pituitary or suprasellar structures, they become symptomatic (3). The symptoms in our case such as visual disturbance, hypopituitarism and diabetes insipidus were thought to be due to the compression of the optic nerve, anterior pituitary, and the hypothalamus. It remains to be clarified, however, why some of them become symptomatic at old age as in the present study.

There are few reports on the CT image of Rathke's cleft cysts. In four cases reported $(3,8,10$, 12), Rathke's cleft cysts were shown to appear as nonenhancing-noncalcified low dense sellar/suprasellar cysts. Another case with Rathke's cleft cyst showed empty sella (11) and the sixth case showed a contrast-enhancing CT lesion in the suprasellar cistern (9). Our case showed nonenhancing noncalcified CT lesion and although MRI could not lead to the diagnosis of Rathke's cleft cyst in this case, it revealed more remarkable mass with suprasellar extension. Therefore it may be possible 
that MRI is useful for the further diagnosis of Rathke's cleft cyst.

\section{REFERENCES}

1) Naiken VS, Tellem M, Meranze DR: Pituitary cyst of Rathke's cleft origin with hypopituitarism. J Neurosurg 18: 703, 1961.

2) Martin JB, Richardson EP Jr., Hyslop NE Jr., et al: Case records of the Massachusetts General Hospital: case 17-1980. N Engl J Med 302: 1015, 1980.

3) Steinberg GK, Koenig GH, Golden JB: Symptomatic Rathke's cleft cysts. J Neurosurg 56: 290, 1982.

4) Yoshida J, Kobayashi T, Kageyama N, et al: Symptomatic Rathke's cleft cyst. J Neurosurg 47: 451, 1977.

5) Trokoudes KM, Walfish PG, Holgate RC, et al: Sellar enlargement with hyperprolactinemia and a Rathke's pouch cyst. JAMA 240: 471, 1978.

6) Kobayashi T, Yoshida J, Kageyama N: A case of recurrent Rathke's cleft cyst-discussion on its biological nature from clinical course, pathological studies and review of literatures. No Shinkei Geka 6: 437, 1978.

7) Saito Y, Nakaya Y, Takami M: Pituitary cyst-case report. No Shinkei Geka 7: 119, 1979.

8) Martinez LJ, Osterholm JL, Berry RG, et al: Transsphenoidal removal of a Rathke's cleft cyst. Neurosurgery 4: 63, 1979.

9) Kapcala LP, Molitch ME, Post KD, et al: Galactorrhea, oligo/amenorrhea, and hyperprolactinemia in patients with craniopharyngiomas. J Clin Endocrinol Metab 51: 798, 1980.

10) Byrd SE, Winter J, Takahashi M, et al: Symptomatic Rathke's cleft cyst demonstrated on computed tomography. J Comput Assist Tomogr 4: 411, 1980.

11) Baldini M, Mosca L, Princi L: The empty sella syndrome secondary to Rathke's cleft cyst. Acta Neurochirurgica 53: 69, 1980.

12) Nagasaka S, Kuromatsu C, Wakisaka S, et al: Rathke's cleft cyst. Surg Neurol 15: 402, 1980.

13) Rout D, Das L, Rao VRK, et al: Symptomatic Rathke's cleft cysts. Surg Neurol 19: 42, 1983. 